\title{
Parental History of Atopic Diseases and Presence of Allergic Rhinitis and Asthma in Children with Atopic Dermatitis
}

\author{
Tatjana Gazibara', Vesna Reljićn ${ }^{2,3}$, Miloš Nikolićn ${ }^{2,3}$, Nataša Maksimović ${ }^{1}$ \\ ${ }^{1}$ Institute of Epidemiology, University of Belgrade, Faculty of Medicine, Belgrade, Serbia, 2Clinic of Dermatovenereology, \\ Clinical Center of Serbia, Belgrade, Serbia, 3Department of Dermatovenereology, University of Belgrade, Faculty of Medicine, \\ Belgrade, Serbia
}

Correspondence: natamax07@yahoo.com; Tel./Fax.: + 381113607062

Received: December 4, 2019; Accepted: January 12, 2020

\begin{abstract}
Objective - To assess the prevalence of allergic rhinitis and asthma in children with and without parental history of atopic dermatitis (AD) as well as to explore the association between parental history of atopic diseases and presence of allergic rhinitis or asthma in children diagnosed with AD. Methods - From January to June 2014, we recruited a total of 98 children with AD and their parents who presented at the Clinic of Dermatovenereology, Clinical Center of Serbia, Belgrade, Serbia. The parents filled in a questionnaire. The severity of AD was assessed using the SCORing Atopic Dermatitis (SCORAD) Index. Results - Of 98 parents, $33(33.7 \%)$ reported having history of $\mathrm{AD}$. In children with parental history of $\mathrm{AD}$, the prevalence of allergic rhinitis and asthma was $18.2 \%$ and $24.2 \%$, respectively. In children without parental history of AD, the prevalence of allergic rhinitis and asthma was $12.3 \%$ and $23.1 \%$, respectively. Adjusted logistic regression analyses showed that: neither mothers' nor fathers' history $\mathrm{AD}$ were associated with presence of allergic rhinitis or asthma; fathers' history of asthma was associated with presence of asthma and mothers' history of asthma was associated with presence of allergic rhinitis. Fathers' history of allergic rhinitis was associated with presence of allergic rhinitis and mothers' history of allergic rhinitis was associated with presence of asthma. Conclusion - Our findings suggest that, compared to parental history of AD, parental history of asthma and allergic rhinitis were stronger contributors to the presence of atopic comorbid disorders in children with AD.
\end{abstract}

Key Words: Atopic Dermatitis • Children - Comorbidity - Parents • Atopy.

\section{Introduction}

Atopic dermatitis (AD) is a chronic skin disease that usually appears during childhood. The estimated worldwide prevalence of $\mathrm{AD}$ in children altogether is approximately $7 \%$ (1). In infants, however, the prevalence is often up to $20 \%$ (2). Children with $\mathrm{AD}$ may have physical, psychological and psychosocial difficulties due to $\mathrm{AD}$ (3). Specifically, the physical impact of $\mathrm{AD}$ refers to itching, scratching and visible changes of the skin (3). Mood swings, irritability, disrupted sleep or lack of sleep account for the psychological impact of $\mathrm{AD}$ on child's life $(3,4)$. The psychosocial impact of $\mathrm{AD}$ comprises restriction in social contact, teasing and embarrassment $(3,5)$. Because of these features, $\mathrm{AD}$ often has unfavorable effect on family functioning as a whole (6).

It is estimated that more than half of children with $\mathrm{AD}$ are at risk of developing concomitant atopic diseases such as allergic rhinitis or asthma (7). Presence of comorbidity might predispose progression and persistence of $\mathrm{AD}(8)$. A prospective cohort study of more than 1,000 children from 5 Western European countries found that phenotype plays an important role in timing and clinical course of $\mathrm{AD}$ (9). This study also found that chil- 
dren whose parents previously had allergies were 5 times more likely to develop $\mathrm{AD}$, allergic rhinitis or asthma (9). Similar findings on the association of family AD history with the development of respiratory allergies among children with $\mathrm{AD}$ were observed in a cohort of children from Bosnia and Herzegovina (10). While origins of $\mathrm{AD}$ are not entirely clear, compelling evidence suggests that parental history of $\mathrm{AD}$ can be a risk factor for $\mathrm{AD}$ or other atopic diseases, such as allergic rhinitis or asthma in their children (7-10). We hypothesized that parental history of $\mathrm{AD}$, asthma and allergic rhinitis is associated with presence of allergic rhinitis and asthma comorbidity in children with AD.

The aim of this study was to 1) assess the prevalence of allergic rhinitis and asthma in children with and without parental history of $\mathrm{AD}$ and 2) to explore the association of parental history of atopic diseases with presence of allergic rhinitis and asthma in children with $\mathrm{AD}$.

\section{Methods}

\section{Participants}

This study is part of a comprehensive study on ADrelated quality of life among children with $\mathrm{AD}$ and their parents (11). While the previous study included a prospective cohort design (11), this analysis is performed using a cross-sectional study methodology. From January to June 2014, we recruited 98 children with $\mathrm{AD}$ and their parents who presented at the Clinic of Dermatovenereology, Clinical Center of Serbia, Belgrade, Serbia. The sample size was calculated using Raosoft sample size calculator (12) based on margin of error of 5\%, confidence interval od 95\%, population size of children aged 0-18 years residing in Belgrade of 300,000, and worldwide prevalence of $\mathrm{AD}$ (response distribution) of $7 \%$ (1). The calculated sample size was 100.

The diagnosis of $\mathrm{AD}$ in children was made according to Hanifin and Rajka diagnostic criteria (13). All children were treated with emollient creams, topical mid-potency corticosteroids (mometasone furoate, fluocinolone acetonide or betamethasone dipropionate), and oral second-genera- tion non-sedating antihistamines (desloratadin or levocetirizin) according to the clinical presentation. The inclusion criteria were: confirmed diagnosis of $\mathrm{AD}$ in children, absence of other skin diseases and the ability of parents to speak and understand Serbian language.

\section{Data Collection}

The parents of children with $\mathrm{AD}$ were asked to fill in a questionnaire. The questionnaire was divided in two segments: one referred to child's characteristics and the other referred to parental characteristics. The questionnaire examined the following child's characteristics: gender, age, duration of $\mathrm{AD}$, whether or not the child has had allergic rhinitis or asthma. Parents provided information about their age, education level, number of children in the household and birth order of the child with whom they presented at the Clinic as well as about family history of $\mathrm{AD}$, asthma and allergic rhinitis (Appendix).

The majority of children with $\mathrm{AD}$ (more than $80 \%)$ presented with both parents. On that occasion, the parents were invited to participate in this study. However, both parents filled in one single questionnaire together. Because of this, we were not able to specify parental gender within their demographic characteristic.

The severity of $\mathrm{AD}$ in children was examined by a treating dermatologist, using the SCORing Atopic Dermatitis (SCORAD) Index (14). The SCORAD consists of three different aspects: 1) extent, 2) severity and 3) subjective feelings. First, the extent of the affected skin is calculated using the "rule of nine" (head and neck account for 9\%, upper limbs account for $9 \%+9 \%=18 \%$, each lower limb accounts for $18 \%$, anterior trunk and back each account for $18 \%$ and genitals account for $1 \%)$. The percentages for each body area affected by $\mathrm{AD}$ is added up, which means that the extent of $\mathrm{AD}$ can be numerically expressed from 0 (minimum) to 100 (maximum) depending on the skin surface affected by AD. This part makes $20 \%$ of the SCORAD score. This means that the raw score for the extent of $\mathrm{AD}$ is divided by 5 . The range of score is $0-20$. 
Second, grading of severity of $\mathrm{AD}$ is based on six elements: erythema, edema/papulation, oozing/ crusts, excoriations, lichenification and dryness. Each of these elements is graded on a 4-point scale, from 0 to 3 where 0 refers to absence, 1 refers to mild change, 2 refers to moderate change and 3 refers severe change. Grading is performed on a part of skin with neither the most intense nor the least intense changes. In this way, the average change of all the affected areas is representative of AD intensity. Scores for each element are added in a summary score which ranges from 0 to 18 . This part makes $60 \%$ of the SCORAD score. This means that the score needs to be mathematically adjusted according to the formula $7 \mathrm{x}$ severity score / 2 . The range of severity score is from 0 to 63 .

Third, subjective feeling of pruritus and sleeplessness is added to the previous two scores. The two subjective feelings are rated on a visual scale from 0 (no itch, no sleeplessness) to 10 (severe itch, severe sleeplessness). Because SCORAD measures two subjective feelings, this score ranges from 0 to 20 . This part also makes $20 \%$ to the SCORAD score. The SCORAD score is obtained by summing scores for each of the three examined parts. The SCORAD score ranges from 0 to $103(20+63+20)$. Higher scores denote higher degree of $\mathrm{AD}$ extend and severity (15).

\section{Ethics Statement}

This study was approved by the Ethics Committee of the Faculty of Medicine, University of Belgrade (Approval no. 29/XII-21). All the parents provided signed informed consent for participation in the study.

\section{Data Analysis}

The Statistical Package for Social Sciences (SPSS), version 20 (SPSS Inc, Chicago, IL, USA) was used to analyze the data. Normality of distribution for parental and children's characteristics was examined using the Kolmogorov Smirnov test. Children's age, number of children in the family and $\mathrm{AD}$ duration were not normally distributed. These variables were described using median and corresponding inter- quartile range (IR). Characteristics that were normally distributed were presented as mean with corresponding standard deviation (SD). Differences in characteristics of parents and children according to parental history of $\mathrm{AD}$ were evaluated using the following tests: 1) t-test for 2 independent samples (for normally distributed continuous variables parental age, SCORAD), 2) Mann Whitney U test (for not normally distributed continuous variables - children's age, AD duration and number of children in the family), 3) Chi square test and Chi square linear-by-linear association (for categorical variables with two and three categories, respectively, as well as when number of observations per cell was 5 and above) and 4) Fisher's exact test (for categorical variables when number of observations per cell was below 5).

Parental history of AD was analyzed separately for mothers and for fathers as well as a combined variable labelled 'parental history' (where history of $\mathrm{AD}$ for mothers and fathers was observed as a single variable). To examine the association of parental history of $\mathrm{AD}$, asthma and allergic rhinitis with presence of allergic rhinitis or asthma comorbidity in children with $\mathrm{AD}$, we used the logistic regression models. The models were divided according to the exposures: 1) history of $\mathrm{AD}, 2$ ) asthma and 3) allergic rhinitis. The exposure was divided in two independent variables: mothers' and fathers' history of $\mathrm{AD}$, asthma and allergic rhinitis, respectively. Other independent variables (covariates) in the models were child's and parental demographic characteristics (child's age and gender, parental age and education level and child's birth order) and child's $A D$ characteristics (AD duration and SCORAD score). The dependent variables in all three models were presence of allergic rhinitis and asthma in children with AD (yes/no). Probability level of $\mathrm{P}<0.05$ was considered as the limit of statistical significance.

\section{Results}

A total of 98 parent-child pairs were included in the study. Thirty-three parents reported having history of $\operatorname{AD}(33.7 \%)$. Of those, $20(60.6 \%)$ were fathers and $13(39.4 \%)$ were mothers. Socio-demographic 
and AD-related characteristics according to family $\mathrm{AD}$ history are presented in Table 1 . Of all the examined variables, only parental education level and birth order of children with $\mathrm{AD}$ differed between the parents with and without history of $\mathrm{AD}$. In our sample, there were more highly educated parents with history of $\mathrm{AD}$. Also, parents with history of $\mathrm{AD}$ had more children with $\mathrm{AD}$ who were born later (Table 1).
In children with $\mathrm{AD}$, asthma was more often reported compared to allergic rhinitis. The prevalence of allergic rhinitis and asthma did not differ between children with and without parental history of $\mathrm{AD}$. In children who had parental history of $\mathrm{AD}$, the prevalence of allergic rhinitis was $18.2 \%$ and of asthma $24.2 \%$. In children without parental history of $\mathrm{AD}$, the prevalence of allergic rhinitis was $12.3 \%$ and of asthma $23.1 \%$.

\section{Table 1. Socio-Demographic Characteristics of Parents and Children with Atopic Dermatitis}

\begin{tabular}{|c|c|c|c|}
\hline Variable & $\begin{array}{l}\text { Positive parental history of AD } \\
\mathrm{N}=33\end{array}$ & $\begin{array}{l}\text { Negative parental history of } \mathrm{AD} \\
\mathrm{N}=65\end{array}$ & $\mathrm{P}$ \\
\hline \multicolumn{4}{|l|}{ Parental characteristics } \\
\hline Age in years $($ mean $\pm S D)$ & $38.7 \pm 4.2$ & $36.8 \pm 6.0$ & 0.101 \\
\hline \multicolumn{4}{|l|}{ Highest education attainment } \\
\hline Primary school & $0(0)$ & $2(3.1)$ & \\
\hline Secondary school & $7(21.2)$ & $31(47.7)$ & \\
\hline Higher education & $26(78.8)$ & $32(49.0)$ & 0.004 \\
\hline \multicolumn{4}{|l|}{ Having asthma } \\
\hline Yes & $10(30.3)$ & $17(26.2)$ & \\
\hline No & $23(69.7)$ & $48(73.8)$ & 0.664 \\
\hline \multicolumn{4}{|l|}{ Having allergic rhinitis } \\
\hline Yes & $12(36.2)$ & $17(26.2)$ & \\
\hline No & $21(63.8)$ & $48(73.8)$ & 0.295 \\
\hline \multicolumn{4}{|l|}{ Children's characteristics } \\
\hline \multicolumn{4}{|l|}{ Gender } \\
\hline Male & $21(63.6)$ & $33(50.8)$ & \\
\hline Female & $12(36.4)$ & $32(49.2)$ & 0.226 \\
\hline Median age in years (IR) & $4.5(7.7)$ & $7.0(9.4)$ & 0.293 \\
\hline \multicolumn{4}{|l|}{ Birth order of the child with $\mathrm{AD}$} \\
\hline First & $19(57.6)$ & $52(80.0)$ & \multirow{3}{*}{0.008} \\
\hline Second & $12(36.4)$ & $13(20.0)$ & \\
\hline Third & $2(6.1)$ & $0(0)$ & \\
\hline Median duration of disease (IR) & $3.0(7.0)$ & $4.5(7.7)$ & 0.576 \\
\hline \multicolumn{4}{|l|}{ Having allergic rhinitis } \\
\hline Yes & $6(18.2)$ & $8(12.3)$ & \\
\hline No & $27(81.8)$ & $57(87.7)$ & 0.432 \\
\hline \multicolumn{4}{|l|}{ Having asthma } \\
\hline Yes & $8(24.2)$ & $15(23.1)$ & \\
\hline No & $25(75.8)$ & $50(76.9)$ & 0.898 \\
\hline SCORAD $($ mean $\pm S D)$ & $36.9 \pm 15.2$ & $33.4 \pm 15.0$ & 0.279 \\
\hline
\end{tabular}

$\mathrm{AD}=$ Atopic dermatitis; $\mathrm{SD}=$ Standard deviation; IR=Interquartile range; SCORAD=Scoring Atopic Dermatitis Index; Values in brackets represent corresponding percentages; Difference in continuous variables presented as mean $\pm \mathrm{SD}$ was examined using t-test for 2 independent samples; Differences in continuous variables presented as median (IR) were examined using Mann-Whitney U test; Differences in categorical variables were examined using Chi square linear-by-linear association (parental education level, birth order) and Chi square test (child's gender, having asthma and having rhinitis). 
Table 2. Prevalence of Atopic Comorbidity in Children with Atopic Dermatitis According to Disease Severity Based on the Median Scoring Atopic Dermatitis Index Score and Parental History of Atopic Dermatitis

\begin{tabular}{|c|c|c|c|c|c|c|}
\hline \multirow{4}{*}{ Variable } & \multicolumn{6}{|l|}{ SCORAD } \\
\hline & \multicolumn{3}{|c|}{ SCORAD $\leq 32.6(\mathrm{~N}=49)$} & \multicolumn{3}{|c|}{ SCORAD >32.6 $(\mathrm{N}=49)$} \\
\hline & \multicolumn{6}{|c|}{ Parental history of $\mathrm{AD}$} \\
\hline & Yes $(N=12)$ & No $(\mathrm{N}=37)$ & $\mathrm{P}$ & Yes $(\mathrm{N}=21)$ & No $(\mathrm{N}=28)$ & $\mathrm{P}$ \\
\hline Having AR (N; \%) & $1(8.3)$ & $4(10.3)$ & 0.644 & $5(23.8)$ & $4(14.3)$ & 0.314 \\
\hline Having A (N; \%) & $1(8.3)$ & $10(27.0)$ & 0.252 & $7(33.3)$ & $5(14.3)$ & 0.213 \\
\hline
\end{tabular}

$\mathrm{AD}=$ Atopic dermatitis; $\mathrm{AR}=$ Allergic rhinitis; $\mathrm{A}=\mathrm{Asthma}$; $\mathrm{SCORAD=Scoring} \mathrm{Atopic} \mathrm{Dermatitis} \mathrm{Index.} \mathrm{Differences} \mathrm{for} \mathrm{variables} \mathrm{where} \mathrm{cells} \mathrm{had}$ count of less than 5 were tested using Fisher's exact test. Variables with count of 5 and above were tested using Chi square test.

Median SCORAD index was 32.6. A total of 24.5\% (12/49) children whose AD severity scored below median SCORAD had parental history of $\mathrm{AD}$. On the other hand, $42.8 \%$ (21/49) of children whose $\mathrm{AD}$ severity scored above median SCORAD had parental history of AD. The difference was not deemed statistically significant $\left(\chi^{2}=3.700 ; \mathrm{P}=0.054\right)$. Although not reaching statistical significance level, there was a tendency among children with higher SCORAD scores to have parental history of AD.

The prevalence of allergic rhinitis and asthma among children who were classified as having more severe $\mathrm{AD}$ (SCORAD above median value) were $18.4 \%(9 / 49)$ and $24.5 \%$ (12/49), respectively. The prevalence of allergic rhinitis and asthma among children who were classified as having less severe AD (SCORAD below median value) were $10.2 \%(5 / 49)$ and $22.4 \%$ (11/49), respectively. The observed difference was not statistically significant $\left(\chi^{2}=0.949 ; \mathrm{P}=0.323\right)$. When children with $\mathrm{AD}$ were stratified according to mean SCORAD value and parental history of $\mathrm{AD}$, no difference in the prevalence of allergic rhinitis and asthma was observed (Table 2).
Correlation coefficients between the examined variables and their probability values are presented in Table 3. Having parental history of AD correlated with higher education level of the parents. Having parental history of asthma correlated with presence of asthma and allergic rhinitis in children with $\mathrm{AD}$. Having parental history of allergic rhinitis correlated only with child's allergic rhinitis. In children, having asthma correlated with having allergic rhinitis, male gender, older age of the parents, later birth order and longer AD duration. Having allergic rhinitis in children correlated with older age of both children and parents and longer $\mathrm{AD}$ duration (Table 3).

The association of parental AD with child's allergic rhinitis and asthma is presented in Table 4. Neither mothers' nor fathers' history of AD were associated with presence of allergic rhinitis or asthma in children with $\mathrm{AD}$. Older age of the parents was associated with presence of allergic rhinitis. Older age of children with AD and later birth order were associated with presence of asthma (Table 4). 


\begin{tabular}{|c|c|c|c|c|c|c|c|c|c|c|c|c|}
\hline Variables & $\begin{array}{l}\text { Correlation } \\
\text { coefficients }\end{array}$ & $\begin{array}{l}\text { Parents } \\
\mathrm{AD}\end{array}$ & $\begin{array}{l}\text { Parents } \\
\text { asthma }\end{array}$ & $\begin{array}{l}\text { Parents } \\
\text { rhinitis }\end{array}$ & $\begin{array}{l}\text { Child } \\
\text { asthma }\end{array}$ & $\begin{array}{l}\text { Child } \\
\text { rhinitis }\end{array}$ & $\begin{array}{l}\text { Child } \\
\text { age }\end{array}$ & $\begin{array}{l}\text { Child } \\
\text { gender }\end{array}$ & $\begin{array}{l}\text { Parents } \\
\text { age }\end{array}$ & $\begin{array}{l}\text { Parents } \\
\text { education }\end{array}$ & $\begin{array}{l}\text { Birth } \\
\text { order }\end{array}$ & $\begin{array}{l}\mathrm{AD} \\
\text { duration }\end{array}$ \\
\hline \multirow{2}{*}{ Parents AD } & rho & - & - & - & - & - & - & - & - & - & - & - \\
\hline & $\mathrm{P}$ & - & - & - & - & - & - & - & - & - & - & - \\
\hline \multirow{2}{*}{$\begin{array}{l}\text { Parents } \\
\text { asthma }\end{array}$} & rho & 0.044 & - & - & - & - & - & - & - & - & - & - \\
\hline & $\mathrm{P}$ & 0.668 & - & - & - & - & - & - & - & - & - & - \\
\hline \multirow{2}{*}{$\begin{array}{l}\text { Parents } \\
\text { rhinitis }\end{array}$} & rho & 0.106 & 0.251 & - & - & - & - & - & - & - & - & - \\
\hline & $\mathrm{P}$ & 0.300 & 0.013 & - & - & - & - & - & - & - & - & - \\
\hline \multirow{2}{*}{$\begin{array}{l}\text { Child } \\
\text { asthma }\end{array}$} & rho & 0.013 & 0.305 & -0.148 & - & - & - & - & - & - & - & - \\
\hline & $\mathrm{P}$ & 0.899 & 0.002 & 0.146 & - & - & - & - & - & - & - & - \\
\hline \multirow{2}{*}{$\begin{array}{l}\text { Child } \\
\text { rhinitis }\end{array}$} & rho & 0.079 & 0.270 & 0.246 & 0.256 & - & - & - & - & - & - & - \\
\hline & $\mathrm{P}$ & 0.437 & 0.007 & 0.014 & 0.011 & - & - & - & - & - & - & - \\
\hline \multirow{2}{*}{ Child age } & rho & -0.122 & -0.004 & -0.102 & 0.033 & 0.229 & - & - & - & - & - & - \\
\hline & $\mathrm{P}$ & 0.230 & 0.968 & 0.316 & 0.750 & 0.023 & - & - & - & - & - & - \\
\hline \multirow{2}{*}{ Child gender } & rho & -0.107 & -0.189 & -0.136 & 0.389 & -0.075 & 0.217 & - & - & - & - & - \\
\hline & $\mathrm{P}$ & 0.295 & 0.063 & 0.183 & 0.001 & 0.461 & 0.032 & - & - & - & - & - \\
\hline \multirow{2}{*}{ Parents age } & rho & 0.162 & 0.092 & 0.036 & 0.328 & 0.355 & 0.577 & 0.143 & - & - & - & - \\
\hline & $\mathrm{P}$ & 0.112 & 0.369 & 0.722 & 0.001 & 0.001 & 0.001 & 0.161 & - & - & - & - \\
\hline \multirow{2}{*}{$\begin{array}{l}\text { Parents } \\
\text { education }\end{array}$} & rho & 0.289 & 0.102 & 0.181 & -0.040 & -0.010 & -0.020 & -0.003 & 0.121 & - & - & - \\
\hline & $\mathrm{P}$ & 0.004 & 0.319 & 0.075 & 0.698 & 0.925 & 0.847 & 0.974 & 0.236 & - & - & - \\
\hline \multirow{2}{*}{ Birth order } & rho & -0.010 & -0.065 & -0.154 & 0.253 & 0.004 & 0.105 & 0.041 & 0.181 & -0.060 & - & - \\
\hline & $\mathrm{P}$ & 0.922 & 0.522 & 0.130 & 0.012 & 0.969 & 0.303 & 0.691 & 0.074 & 0.560 & - & - \\
\hline \multirow{2}{*}{$\mathrm{AD}$ duration } & rho & -0.057 & -0.028 & -0.114 & 0.260 & 0.252 & 0.840 & 0.133 & 0.471 & -0.065 & 0.153 & - \\
\hline & $\mathrm{P}$ & 0.578 & 0.786 & 0.265 & 0.010 & 0.013 & 0.001 & 0.192 & 0.001 & 0.527 & 0.133 & - \\
\hline \multirow{2}{*}{ SCORAD } & rho & 0.111 & 0.157 & 0.057 & 0.085 & 0.073 & 0.015 & -0.011 & 0.062 & -0.015 & 0.046 & 0.018 \\
\hline & $\mathrm{P}$ & 0.278 & 0.126 & 0.581 & 0.407 & 0.477 & 0.881 & 0.915 & 0.547 & 0.882 & 0.650 & 0.859 \\
\hline
\end{tabular}

Legend: $\mathrm{AD}=$ Atopic dermatitis; $\mathrm{SCORAD}=$ Scoring Atopic Dermatitis Index.

Table 4. Adjusted Regression Model Examining the Association of Parental History of Atopic Dermatitis with Allergic Rhinitis and Asthma in Children with Atopic Dermatitis

\begin{tabular}{lll}
\hline Variables & $\begin{array}{l}\text { Allergic rhinitis } \\
\text { OR }(95 \% \mathrm{CI})\end{array}$ & $\begin{array}{l}\text { Asthma } \\
\text { OR }(95 \% \mathrm{CI})\end{array}$ \\
\hline Mother's history of AD & $0.87(0.07-10.35)$ & $0.16(0.01-2.08)$ \\
\hline Father's history of AD & $1.66(0.31-8.92)$ & $1.32(0.27-6.40)$ \\
\hline Child's age & $0.93(0.73-1.20)$ & $1.34(1.08-1.66) \dagger$ \\
\hline Child's gender & $0.51(0.13-1.91)$ & $0.77(0.24-2.42)$ \\
\hline Parental age & $1.26(1.07-1.49)^{\dagger}$ & $1.06(0.92-1.23)$ \\
\hline Parental education level & $0.76(0.21-2.70)$ & $0.72(0.25-2.06)$ \\
\hline Birth order & $0.71(0.20-2.55)$ & $3.41(1.16-10.03)^{*}$ \\
\hline AD duration & $1.13(0.88-1.46)$ & $0.90(0.74-1.09)$ \\
\hline SCORAD & $1.02(0.98-1.06)$ & $1.01(0.98-1.05)$ \\
\hline
\end{tabular}

$\mathrm{AD}=$ Atopic dermatitis; $\mathrm{SCORAD}=$ Scoring Atopic Dermatitis Index; $\mathrm{OR}=$ Odds ratio; $\mathrm{CI}=$ Confidence interval; ${ }^{\star} \mathrm{P}<0.05$; ${ }^{\dagger} \mathrm{P}<0.01$. 
Table 5 illustrates the associations between having parental history of asthma with presence of allergic rhinitis and asthma among children with $\mathrm{AD}$. In this model, we observed that fathers' history of asthma was associated with presence of asthma in children with AD. Mothers' history of asthma was associated with presence of allergic rhinitis in children with $\mathrm{AD}$. Older age of the parents was associated with presence of allergic rhinitis. Older age of children with $\mathrm{AD}$ and later birth order were associated with presence of asthma (Table 5).
The results of the last logistic regression model are shown in Table 6 . Father's history of allergic rhinitis was associated with presence of allergic rhinitis in children with AD. Mothers' history of allergic rhinitis was associated with presence of asthma in children with $\mathrm{AD}$. Older age of the parents was associated with presence of allergic rhinitis. Older age of children with $\mathrm{AD}$ was associated with presence of asthma (Table 6).

\begin{tabular}{|c|c|c|}
\hline Variables & $\begin{array}{l}\text { Allergic rhinitis } \\
\text { OR }(95 \% \mathrm{CI})\end{array}$ & $\begin{array}{l}\text { Asthma } \\
\text { OR }(95 \% \text { CI })\end{array}$ \\
\hline Mother's history of asthma & $5.52(1.02-29.93)^{*}$ & $2.31(0.41-12.92)$ \\
\hline Father's history of asthma & $2.72(0.49-15.11)$ & $68.34(6.77-689.73)^{\dagger}$ \\
\hline Child's age & $0.94(0.73-1.22)$ & $1.55(1.14-2.11)^{\dagger}$ \\
\hline Child's gender & $0.71(0.17-2.85)$ & $0.93(0.24-3.62)$ \\
\hline Parental age & $1.29(1.08-1.54)^{\dagger}$ & $0.97(0.81-1.17)$ \\
\hline Parental education level & $0.77(0.21-2.96)$ & $0.41(0.12-1.39)$ \\
\hline Birth order & $0.72(0.20-2.57)$ & $4.81(1.31-17.67)^{*}$ \\
\hline $\mathrm{AD}$ duration & $1.12(0.86-1.46)$ & $0.90(0.70-1.15)$ \\
\hline SCORAD & $1.01(0.97-1.06)$ & $0.99(0.96-1.04)$ \\
\hline
\end{tabular}

$\mathrm{AD}=$ Atopic dermatitis; $\mathrm{SCORAD}=\mathrm{S}$ coring Atopic Dermatitis Index; $\mathrm{OR}=\mathrm{Odds}$ ratio; $\mathrm{CI}=$ Confidence interval. ${ }^{*} \mathrm{P}<0.05$; ${ }^{\dagger} \mathrm{P}<0.01$.

Table 6. Adjusted Regression Model Examining the Association of Parental History of Allergic Rhinitis with Allergic Rhinitis and Asthma in Children with Atopic Dermatitis

\begin{tabular}{lll}
\hline Variables & $\begin{array}{l}\text { Allergic rhinitis } \\
\text { OR }(95 \% \mathrm{CI})\end{array}$ & $\begin{array}{l}\text { Asthma } \\
\text { OR }(95 \% \mathrm{CI})\end{array}$ \\
\hline Mother's history of allergic rhinitis & $2.23(0.47-10.60)$ & $1.08(1.01-1.89)^{*}$ \\
\hline Father's history of allergic rhinitis & $6.38(1.01-40.63)^{*}$ & $2.42(0.35-16.62)$ \\
\hline Child's age & $0.91(0.68-1.21)$ & $1.29(1.05-1.59)^{*}$ \\
\hline Child's gender & $0.64(0.16-2.58)$ & $0.60(0.18-1.99)$ \\
\hline Parental age & $1.26(1.06-1.51)^{\dagger}$ & $1.11(0.95-1.30)$ \\
\hline Parental education level & $0.67(0.19-2.45)$ & $0.61(0.20-1.85)$ \\
\hline Birth order & $0.75(0.20-2.75)$ & $2.48(0.85-7.21)$ \\
\hline AD duration & $1.19(0.89-1.59)$ & $0.93(0.76-1.12)$ \\
\hline SCORAD & $1.02(0.98-1.07)$ & $1.02(0.98-1.05)$ \\
\hline
\end{tabular}

$\mathrm{AD}=$ Atopic dermatitis; $\mathrm{SCORAD}=$ Scoring Atopic Dermatitis Index; $\mathrm{OR}=$ Odds ratio; $\mathrm{CI}=$ Confidence interval; ${ }^{*} \mathrm{P}<0.05$; ${ }^{\dagger} \mathrm{P}<0.01$. 


\section{Discussion}

In our sample of children with $\mathrm{AD}$ asthma was more prevalent compared to allergic rhinitis. There was no difference in the prevalence of allergic rhinitis or asthma between children with and without parental history of AD. Similar results were observed when the children were additionally stratified according to $\mathrm{AD}$ severity. This study also found that presence of parental atopic diseases were not consistently associated with atopic comorbidity in children with $\mathrm{AD}$, because having parental history of $A D$ was not associated with either allergic rhinitis or asthma among children with $\mathrm{AD}$. Concordance between atopic entities was seen between fathers and children with AD. Specifically, fathers' history of asthma was associated with presence of asthma and mothers' history of asthma was associated with presence of allergic rhinitis in children with AD. Fathers' history of allergic rhinitis was associated with presence of allergic rhinitis and mothers' history of allergic rhinitis was associated with presence of asthma in children with AD.

Studies on children who have atopic comorbidities reported inconsistent findings. For example, in South Africa, the prevalence of allergic rhinitis in children with $\mathrm{AD}$ was $53 \%$ and that of asthma $39 \%$ (16). In this cohort of children (16), atopic disorders such as allergic rhinitis and asthma, as well as sensitivity to aeroallergens had an increasing tendency with advancing age. Studies in Asian population, such as in South Korea (17), reported that the prevalence of $\mathrm{AD}$ and allergic rhinitis were the highest at the age of 4-6 years (10.2\%). Although some decline in the prevalence is seen in later age, no appreciable decrease was observed. Thus, the prevalence of $\mathrm{AD}$ and allergic rhinitis at age $10-13$ years was $7.7 \%$. The pattern of prevalence of asthma in children with $\mathrm{AD}$ was somewhat different. The prevalence was the highest at age 0-3 years $(4.7 \%)$, after which a steady decline was reported. The lowest prevalence was observed among children aged $10-13$ years (1.8\%). In consideration of literature data $(16,17)$ and the prevalence of allergic rhinitis and asthma in children with $\mathrm{AD}$ observed in our study, it can be assumed that ethnic differences in atopic comorbidities exist, and they can be explained by different phenotypes (18).

A previous study showed that parental atopy, especially that of the mothers, was associated with presence of asthma in children (19). Similar findings were observed when the association between parental history of allergic rhinitis and presence of childhood allergic rhinitis was examined (20). A long term perspective study that followed close to 1,000 children with atopic diseases found that parental history of atopy was a strong predictor of atopic comorbidities in their children (21). Also, a recent study suggested that several clusters of $A D$ severity and comorbidity can be identified in children with AD (22). Parental history of asthma and $\mathrm{AD}$ was observed along with the cluster of children who had moderate-severe $\mathrm{AD}$ and high prevalence of comorbidity (22).

In this study, we observed that parental history of atopic diseases was not consistently associated with allergic rhinitis and asthma in children with AD. While previous studies highlight that maternal atopy plays a more important role in the development of atopic disorders in children $(19,20)$, in our sample of parents and children with $\mathrm{AD}$ we observed that both mothers' and fathers' history of asthma and allergic rhinitis contribute to the presence of atopic comorbidities in children with $\mathrm{AD}$. In fact, a concordance between atopic entities was observed between fathers and children with $\mathrm{AD}$. Our results are in line with the previous evidence where fathers' history of asthma has been observed to increase the risk of having asthma in their children (23). Similarly, fathers' allergic rhinitis has been identified as a risk factor for the development of AD (24). Our findings suggest that parental history of asthma and allergic rhinitis are stronger factors associated with the presence of atopic comorbid disorders in children with $\mathrm{AD}$ compared to parental history of allergic rhinitis and $\mathrm{AD}$, probably though genetic pathways transmitted across generations.

The exact etiopathogenesis of $\mathrm{AD}$ and atopic comorbidities in $\mathrm{AD}$ is not fully understood. While longer duration of $\mathrm{AD}$ was not associated 
with the presence of allergic rhinitis or asthma in the regression models, we did find a significant correlation between them. Most authors agree that the underlying mechanisms might be multifactorial, because the evidence suggests that genetics and environmental exposures contribute to the onset of atopic diseases (25). Mutations in the gene coding the protein filaggrin are responsible for the changes in keratinocytes, their differentiation and function. In this way, the affected skin does not represent an adequate barrier (26). The genetic risk score has also been associated with higher risk of persistent $\mathrm{AD}$ (27). Of the intrinsic risk factors, dysfunction of the innate and adaptive immunity with strong T-helper type 2 lymphocyte response has also been observed in persons with $\mathrm{AD}$ (26). Because of the involvement of the immune system in $\mathrm{AD}$, persons with $\mathrm{AD}$ are more likely to have autoimmune illnesses compared to general population (28).

Of the extrinsic factors, skin changes in $\mathrm{AD}$ have been linked to the changes of the skin microbiome, predominantly with regards to $S$. epidermidis (28). The severity of $\mathrm{AD}$ has been associated with reduced levels of serum nutrients, such as omega- 3 and -6 fatty acids, calcium, folate and vitamin $\mathrm{D}(29,30)$ as well as a higher body mass index (31); while supplementation with a concoction of prebiotics and probiotics showed a significant improvement of $\mathrm{AD}$, particularly among children with more severe AD forms (32). Furthermore, immune response to biological agents, such as $S$. aureus, has recently been indicated to influence the severity of $\mathrm{AD}$ (33), while higher levels of house dust mites have been reported to correlate with more severe $\mathrm{AD}$ in children (34). Thus, severe and persistent childhood $\mathrm{AD}$, that represents a risk factor for the development of atopic comorbidities, such as allergic rhinitis or asthma, seems to be the result of complex interplay of genetic and environmental factors. Difficulties in elucidating triggers and causes of severe $\mathrm{AD}$ forms represent a challenge in management and long-term outcomes of AD.

In our study, being born later was associated with higher likelihood of presence of asthma in children with $\mathrm{AD}$. A recent longitudinal study of more than 47,000 children in Japan reported that increased birth order was associated with lower risk of food allergies, but higher risk of developing $\mathrm{AD}$ (35). Our findings contrast some evidence in literature, where having more siblings was suggested to be protective against development of AD (36-39). Several authors reported that children with more siblings (particularly older siblings) were less likely to develop AD, compared to children with less or no siblings (36-39). While this association is not fully understood, one potential explanation is related to the "hygiene theory" (38). This theory suggests that atopic diseases are less frequent in families with more children due to more exposure to various antigens (most commonly originating from infectious agents) that mobilize immune response, which, in turn, protects from allergic sensitization (40).

There are several limitations of this study. The sample size was relatively small. The inclusion of more parent-child pairs could have increased the statistical power of the study. The sample was selected from the largest urban area of the country. Inclusion of parents and children from semi-urban or rural areas could have yielded different results. Therefore, we cannot generalize our results to the entire population of Serbia. The parents' history of atopic diseases was self-reported. Some studies indicate that self-reporting of atopic diseases among the parents is open to bias (41). We have not explicitly analyzed the number of medications or type of therapy for $\mathrm{AD}$. Other factors, such as secondhand smoke exposure, pet keeping, duration of exclusive breastfeeding or use of daycare were not analyzed. Cross-sectional study design, where exposure and outcomes were measured at the same time, cannot provide definite inference on causality.

\section{Conclusion}

To conclude, the prevalence of asthma is higher than prevalence of allergic rhinitis in children with $\mathrm{AD}$. The prevalence of these atopic comorbidities in children with $\mathrm{AD}$ did not differ according to parental history of AD. Parental history of atopic diseases was not consistently associated with pres- 
ence of atopic comorbidities in children with $\mathrm{AD}$. The association between fathers' history of asthma and allergic rhinitis was concordant with the presence of asthma and allergic rhinitis in children with $\mathrm{AD}$. The association between mothers' history of asthma and allergic rhinitis was discordant. Namely, mothers' history of asthma and allergic rhinitis were associated with presence of allergic rhinitis and asthma, respectively.

Acknowledgement: This study was supported by the Ministry of Education, Science and Technological Development of the Republic of Serbia, Project No. 175025. The authors would like to thank all parents and children who took interest in this study.

Authors' Contributions: Conception and design: TG, VR, $\mathrm{MN}$, NM; Acquisition, analysis and interpretation of data: TG, VR, MN, NM; Drafting the article: TG; Revising it critically for important intellectual content: VR, MN, NM; Approved final version of the manuscript: TG, VR, MN, NM.

Conflict of Interest: The authors declare that they have no conflict of interest.

\section{References}

1. Pols DH, Wartna JB, van Alphen EI, Moed H, Rasenberg $\mathrm{N}$, Bindels PJ et al. Interrelationships between atopic disorders in children: a meta-analysis based on ISAAC questionnaires. Plos One. 2015;10:e0131869.

2. Nutten S. Atopic dermatitis: global epidemiology and risk factors. Ann Nutr Metab. 2015;66 (Suppl 1):8-16.

3. Lewis-Jones S. Quality of life and childhood atopic dermatitis: the misery of living with childhood eczema. Int J Clin Pract. 2006;60(8):984-92.

4. Chernyshov PV. Stigmatization and self-perception in children with atopic dermatitis. Clin Cosmet Investig Dermatol. 2016;9:159-66.

5. Bridgman AC, Eshtiaghi P, Cresswell-Melville A, Ramien M, Drucker AM. The Burden of Moderate to Severe Atopic Dermatitis in Canadian Children: A Cross-Sectional Survey. J Cutan Med Surg. 2018;22(4):443-4.

6. Pustisek N, Vurnek Zivkovic M, Situm M. Quality of Life in Families with Children with Atopic Dermatitis. Pediatr Dermatol. 2016;33(1):28-32.

7. Peters N, Peters AT. Atopic dermatitis. Allergy Asthma Proc. 2019;40(6):433-6.

8. Irvine AD, Mina-Osorio P. Disease trajectories in childhood atopic dermatitis: an update and practitioner's guide. Br J Dermatol. 2019;181(5):895-906.
9. Roduit C, Frei R, Depner M, Karvonen AM, Renz H, Braun-Fahrländer C. Phenotypes of Atopic Dermatitis Depending on the Timing of Onset and Progression in Childhood. JAMA Pediatr. 2017;171(7):655-62.

10. Ćosićkić A, Skokić F, Selimović A, Mulić M, Suljendić $S$, Dedić N, et al. Development of Respiratory Allergies, Asthma and Allergic Rhinits in Children with Atopic Dermatitis. Acta Clin Croat. 2017;56(2):308-17.

11. Maksimovic N, Zaric M, Reljic V, Nikolic M, Gazibara T. Factors associated with improvement of quality of life among parents of children with atopic dermatitis: 1-year prospective cohort study. J Eur Acad Dermatol Venereol. In press. DOI $10.1111 / \mathrm{jdv} .15939$.

12. raosoft.com. Database web survey software for gathering information, 2004 by Raosoft, Inc. [updated 2013 December 2; cited 2019 November 14]. Available from: http://www.raosoft.com/samplesize.html.

13. Hanifin J, Rajka G. Diagnostic features of atopic dermatitis. Acta Derm Venereol. 1980; 92(Suppl.):44-7.

14. Consensus Report of the European Task Force on Atopic Dermatitis. Severity scoring of atopic dermatitis: the SCORAD index. Dermatology. 1993;186(1):23-31.

15. Oranje AP, Glazenburg EJ, Wolkerstorfer A, de Waard-van der Spek FB. Practical issues on interpretation of scoring atopic dermatitis: the SCORAD index, objective SCO$\mathrm{RAD}$ and the three-item severity score. Br J Dermatol. 2007;157(4):645-8.

16. Gray CL, Levin ME, Du Toit G. Respiratory comorbidity in South African children with atopic dermatitis. S Afr Med J. 2017;107(10):904-9.

17. Hong S, Son DK, Lim WR, Kim SH, Kim H, Yum HY et al. The prevalence of atopic dermatitis, asthma, and allergic rhinitis and the comorbidity of allergic diseases in children. Environ Health Toxicol. 2012;27:e2012006.

18. Amat F, Soria A, Tallon P, Bourgoin-Heck M, Lambert N, Deschildre A, Just J. New insights into the phenotypes of atopic dermatitis linked with allergies and asthma in children: An overview. Clin Exp Allergy. 2018;48(8):919-34.

19. Indinnimeo L, Porta D, Forastiere F, De Vittori V, De Castro G, Zicari AM et al. Prevalence and risk factors for atopic disease in a population of preschool children in Rome: Challenges to early intervention. Int J Immunopathol Pharmacol. 2016;29(2):308-19.

20. Batlles-Garrido J, Torres-Borrego J, Rubí-Ruiz T, BonilloPerales A, González-Jiménez Y, Momblán-De Cabo J, et al. Prevalence and factors linked to allergic rhinitis in 10 and 11-year-old children in Almería. Isaac Phase II, Spain. Allergol Immunopathol (Madr). 2010;38(3):135-41.

1. Gough H, Grabenhenrich L, Reich A, Eckers N, Nitsche $\mathrm{O}$, Schramm D et al. Allergic multimorbidity of asthma, 
rhinitis and eczema over 20 years in the German birth cohort MAS. Pediatr Allergy Immunol. 2015;26(5):431-7.

21. Galli E, Maiello N, Cipriani F, La Grutta S, Fasola S, Carello R, et al. Atopic dermatitis phenotypes in preschool and school-age children: a latent class analysis. J Investig Allergol Clin Immunol. In press. doi: 10.18176/ jiaci.0409.

22. Alford SH, Zoratti E, Peterson EL, Maliarik M, Ownby DR, Johnson CC. Parental history of atopic disease: disease pattern and risk of pediatric atopy in offspring. J Allergy Clin Immunol. 2004;114(5):1046-50.

23. Bisgaard H, Halkjaer LB, Hinge R, Giwercman C, Palmer C, Silveira L, et al. Risk analysis of early childhood eczema. J Allergy Clin Immunol. 2009;123(6):1355-60.e5.

24. Paller AS, Spergel JM, Mina-Osorio P, Irvine AD. The atopic march and atopic multimorbidity: Many trajectories, many pathways. J Allergy Clin Immunol. 2019;143(1):46-55.

25. Tsakok T, Woolf R, Smith CH, Weidinger S, Flohr C. Atopic dermatitis: the skin barrier and beyond. Br J Dermatol. 2019;180(3):464-474.

26. Thorsteinsdottir S, Stokholm J, Thyssen JP, Nørgaard S, Thorsen J, Chawes BL, et al. Genetic, Clinical, and Environmental Factors Associated With Persistent Atopic Dermatitis in Childhood. 2019;155(1):50-57.

27. Narla S, Silverberg JI. Association between atopic dermatitis and autoimmune disorders in US adults and children: A cross-sectional study. J Am Acad Dermatol. 2019;80(2):382-9.

28. Kim SH, Lee JH, Ly SY. Children with atopic dermatitis in Daejeon, Korea: individualized nutrition intervention for disease severity and nutritional status. Asia Pac J Clin Nutr. 2016;25(4):716-28.

29. Huang CM, Lara-Corrales I, Pope E. Effects of Vitamin D levels and supplementation on atopic dermatitis: A systematic review. Pediatr Dermatol. 2018;35(6):754-60.

30. Koutroulis I, Magnelli L, Gaughan J, Weiner E, Kratimenos P. Atopic dermatitis is more severe in children over the age of two who have an increased body mass index. Acta Paediatr. 2015;104(7):713-7.
31. Ibáńez MD, Rodríguez Del Río P, González-Segura Alsina D, Villegas Iglesias V. Effect of synbiotic supplementation on children with atopic dermatitis: an observational prospective study. Eur J Pediatr. 2018;177(12):1851-8.

32. Totté JEE, Pardo LM, Fieten KB, de Wit J, de Boer DV, van Wamel WJ et al. IgG response against Staphylococcus aureus is associated with severe atopic dermatitis in children. Br J Dermatol. 2018;179(1):118-26.

33. Kim J, Lee S, Woo SY, Han Y, Lee JH, Lee IY et al. The indoor level of house dust mite allergen is associated with severity of atopic dermatitis in children. J Korean Med Sci. 2013;28(1):74-9.

34. Kikkawa T, Yorifuji T, Fujii Y, Yashiro M, Okada A, Ikeda $\mathrm{M}$, et al. Birth order and paediatric allergic disease: A nationwide longitudinal survey. Clin Exp Allergy. 2018;48(5):577-85.

35. Strachan DP, Aït-Khaled N, Foliaki S, Mallol J, Odhiambo J, Pearce $\mathrm{N}$ et al. Siblings, asthma, rhinoconjunctivitis and eczema: a worldwide perspective from the International Study of Asthma and Allergies in Childhood. Clin Exp Allergy. 2015;45(1):126-36.

36. Taylor-Robinson DC, Williams H, Pearce A, Law C, Hope S. Do early-life exposures explain why more advantaged children get eczema? Findings from the U.K. Millennium Cohort Study. Br J Dermatol. 2016;174(3):569-78.

37. Gibbs S, Surridge H, Adamson R, Cohen B, Bentham G, Reading R. Atopic dermatitis and the hygiene hypothesis: a case-control study. Int J Epidemiol. 2004;33(1):199207.

38. Fotopoulou M, Iordanidou M, Vasileiou E, Trypsianis G, Chatzimichael A, Paraskakis E. A short period of breastfeeding in infancy, excessive house cleaning, absence of older sibling, and passive smoking are related to more severe atopic dermatitis in children. Eur J Dermatol. 2018;28(1):56-63.

39. Sheikh A, Strachan DP. The hygiene theory: fact or fiction? Curr Opin Otolaryngol Head Neck Surg. 2004;12(3):2326.

40. Kulig M, Bergmann R, Edenharter G, Wahn U. Does allergy in parents depend on allergy in their children? Recall bias in parental questioning of atopic diseases. Multicenter Allergy Study Group. J Allergy Clin Immunol. 2000;105(2 Pt 1):274-8. 


\section{Appendix}

\section{General questionnaire about children with atopic dermatitis}

\section{General data about the child with atopic dermatitis}

1. Age (years):

2. Sex 1) Male 2) Female

\section{Information about atopic dermatitis}

3. Age of diagnosis of atopic dermatitis

4. Has anybody from the nuclear family ever had atopic dermatitis (mother, father, sister, brother)?
0) No
1) Yes (please specify who

\section{Information about comorbidities}

5. Has the child ever had had allergic rhinitis (hay fever)? 0$)$ No 1 1) Yes

6. Has anybody from the child's nuclear ever had allergic rhinitis (hay fever)? 0) No 1) Yes If you answered 'yes', please specify who it was (mother, father, sister, brother)

7. Has the child ever had had asthma? 0) No 1) Yes

8. Has anybody from the child's nuclear ever had asthma? 0) No 1) Yes If you answered 'yes', please specify who it was (mother, father, sister, brother)

\section{General data about the accompanying parent}

9. Age (years)

10. Sex 1) Male 2) Female

11. Level of education: 1) Elementary school 2) Secondary school 3) College and University

12. Employment status: 1) Employed 2) Unemployed 3) Retired

13. What is the total number of children living in your household?

14. What is the birth order of the child with atopic dermatitis? 